\title{
Comportamento pós-colheita de mandioquinha-salsa revestida com quitosana $^{1}$
}

\author{
Post-harvest behaviour of the arracacha coated with chitosan
}

\author{
Ellen Karine Roco Piffer de Medeiros Buso², Edmar Clemente ${ }^{2 *}$, Kátia Regina Freitas Schwan Estrada², Néstor \\ Antonio Heredia Zárate ${ }^{3}$ e Juliana Santos Batista Oliveira ${ }^{2}$
}

\begin{abstract}
RESUMO - O objetivo da pesquisa foi avaliar a efetividade da quitosana e da embalagem de polietileno associada à refrigeração na qualidade da mandioquinha-salsa cv. Amarela de Senador Amaral. Os tratamentos realizados foram: aplicação de quitosana a 1,5\%; embalagem de polietileno revestida com filme de PVC e controle (não-tratado e com embalagem plástica). As mandioquinhas-salsa foram lavadas, descascadas, sanitizadas e tratadas e em seguida foram armazenadas a $0{ }^{\circ} \mathrm{C}$ durante 18 dias e a $5{ }^{\circ} \mathrm{C}$ sendo conservada por 9 dias, ambos com $95 \%$ UR. O experimento foi disposto em esquema fatorial $2 \times 7 \times 2$ (2 tratamentos $\times 7$ períodos x 2 temperaturas) com 5 repetições, cada uma composta por 5 tubérculos de mandioquinhas-salsa. As avaliações químicas realizadas foram: determinação dos teores de sólidos solúveis, açúcares totais, amido, atividade enzimática da polifenoloxidase e da peroxidase. A quitosana promoveu efeito elicitor de respostas bioquímicas da defesa da mandioquinha-salsa, com aumento significativo nas atividades da polifenoloxidase e da peroxidase.
\end{abstract}

Palavras-chave: Mandioquinha-salsa. Quitosana. Embalagem-qualidade.

\begin{abstract}
The aim of this research was to evaluate the effectiveness of chitosan and polyethylene packaging, associated with refrigeration, on the quality of the arracacha cv. Amarela de Senador Amaral. The treatments carried out were, application of $1.5 \%$ chitosan, polyethylene packaging lined with PVC film, and a control (untreated and in plastic packaging). The arracacha were washed, peeled, sanitised and treated, and then stored at $0{ }^{\circ} \mathrm{C}$ for 18 days and at $5{ }^{\circ} \mathrm{C}$ for 9 days, both at $95 \% \mathrm{RH}$. The experiment was arranged in a $2 \times 7 \times 2$ factorial $(2$ treatments $\times 7$ periods $\mathrm{x}$ 2 temperatures) with 5 replications, each consisting of 5 arracacha tubers. The chemical evaluations performed were: determination of the levels of soluble solids, total sugars, starch and the enzymatic activity of polyphenoloxidase and peroxidase. The chitosan promoted an elicitor effect of biochemical responses in the defences of the arracacha, with a significant increase in the activities of polyphenol oxidase and peroxidase.
\end{abstract}

Key words: Arracacha. Chitosan. Packaging-quality.

\footnotetext{
*Autor para correspondência

${ }^{1}$ Recebido para publicação em 14/09/2011; aprovado em 22/04/2014

Parte da Tese de Doutorado em Agronomia do primeiro autor, com concessão de bolsa de estudo cedida pela CAPES

${ }^{2}$ Programa de Pós-Graduação em Agronomia, Laboratório de Bioquímica de Alimentos, Centro de Ciências Agrárias, Universidade Estadual de

Maringá, Maringá-PR, Brasil, ellenpiffer@gmail.com, eclemente@uem.br, krfsestrada@uem.br, julianaglomer@hotmail.com

${ }^{3}$ Faculdade de Ciências Agrárias, Universidade Federal da Grande Dourados, Dourados-MS, Brasil, nestorzarate@ufgd.edu.br
} 


\section{INTRODUÇÃO}

Nos últimos anos, os consumidores estão mais preocupados quanto à escolha dos alimentos. Como as frutas e hortaliças são fundamentais na dieta alimentar, o consumo desse tipo de alimento tem sido incrementado. Em supermercados, quitandas e sacolões, é cada vez mais comum encontrar frutas e hortaliças já lavadas, higienizadas e embaladas, prontas para o consumo (MELO; SILVA; ALVES, 2011).

Frutas e hortaliças minimamente processadas são, em essência, vegetais que passaram por alterações físicas, isto é, foram descascados, picados, torneados e ralados, e em alguns casos passaram por tratamentos químicos, tornando-os prontos para o consumo ou preparo, mas mantidos no estado fresco e metabolicamente ativos, com propósito de modificar a sua apresentação para consumo visando basicamente estender a vida útil dos alimentos (MORETTI, 2007). Ao contrário da maioria das técnicas de processamento de alimentos, que estabilizam a vida de prateleira dos produtos, o processamento mínimo pode aumentar sua perecibilidade (MELO; SILVA; ALVES, 2011; MORETTI, 2007; OLIVEIRA JÚNIOR et al., 2004).

A embalagem é parte essencial do processamento e da distribuição dos alimentos e deve necessariamente proteger o produto contra danos físicos, contaminação por microorganismos, insetos e roedores e, ainda, controlar a permeação de gases e vapor de água. O sucesso de uma embalagem está relacionado, também, à facilidade de uso e conveniência para o consumidor (MORETTI, 2007).

Dentre as alternativas de conservação de hortaliças que vem sendo estudadas encontra-se a quitosana, polissacarídeo natural, derivado da quitina extraída da carapaça de crustáceos. Devido à sua capacidade de formar um recobrimento semipermeável, a quitosana prolonga a vida pós-colheita, minimizando a taxa de respiração e reduzindo a perda d'água de frutos (BAUTISTA-BAÑOS et al., 2006).

Recobrimentos comestíveis ativamente funcionais, usando aditivos naturais como a quitosana, podem ser importantes na extensão da vida útil de alimentos minimamente processados, funcionando como barreira aos gases,vapord'água,solutose, ainda, garantindosuasegurança microbiológica. Nestes alimentos, microrganismos deterioradores e patogênicos desenvolvem-se geralmente na superfície do produto. Assim, a incorporação de agentes antimicrobianos nas embalagens (recobrimentos) apresenta-se como uma solução econômica e prática para esse problema (WANG, 1992). Além disso, o potencial dos recobrimentos comestíveis na retenção do aroma e como barreira ao oxigênio faz deles uma promissora fonte de estudos nas áreas de tecnologia de alimentos e embalagens (MAYER; HAREL, 1979).
A Arracacia xanthorrhiza apresenta vários problemas pós-colheita, principalmente sua alta perecibilidade e rápida deterioração. De uma maneira geral, considera-se que a vida de prateleira das raízes é de apenas 2-3 dias, quando mantidas sem refrigeração e sem embalagem. Dentre os principais fatores que limitam a conservação e a comercialização pós-colheita da Arracacia xanthorrhiza, estão a incidência de doenças que corresponde a aproximadamente $94 \%$, desidratação excessiva com cerca de 3,5\% e danos mecânicos com 2,5\% de perdas (RIBEIRO et al., 2007; SOUZA; HENZ; PEIXOTO, 2003).

O objetivo da pesquisa foi avaliar a efetividade da quitosana e da embalagem de polietileno associada à refrigeração na qualidade da mandioquinha-salsa cv. Amarela de Senador Amaral.

\section{MATERIAL E MÉTODOS}

A olerícola foi produzida no município de Guarapuava-PR, no período de agosto de 2009 a junho de 2010, em sistema convencional. As mandioquinhassalsa (Arracacia xanthorrhiza) da variedade Amarela de Senador Amaral, acondicionadas em caixas de isopor, foram transportadas para o laboratório de alimentos da Universidade Estadual de Maringá - Campus Avançado de Umuarama. No recebimento, as mandioquinhas-salsa foram selecionadas quanto ao tamanho, formato e sanidade. Os tubérculos foram lavados, descascados e sanitizados com cloro 2,5\% (marca Brilhante) por 10 minutos.

Após a sanitização, os tubérculos foram separados em dois grupos, controle e revestimento (quitosana 1,5\% Polymar Indústria Comércio Importação Exportação Ltda., diluída em solução de ácido cítrico $0,6 \%$ ). O grupo controle foi embalado em bandeja de isopor (poliestireno $18 \times 11 \times 2,3 \mathrm{~cm}$ ) envolta com filme PVC (policloreto de vinila com espessura de $9 \mu \mathrm{m}$ ). Os tubérculos que foram revestidos com quitosana (imersão dos tubérculos por 2 minutos) também foram embalados em bandeja de isopor envolta com filme PVC. Os dois grupos foram armazenados nas temperaturas 0 e $5^{\circ} \mathrm{C}$ por 18 dias, com $95 \%$ de umidade relativa (UR), sendo avaliados a cada três dias.

O delineamento experimental foi inteiramente casualizado em esquema fatorial $2 \times 7 \times 2$ ( 2 tratamentos x 7 períodos $(0 ; 5 ; 10 ; 15 ; 20 ; 25$ e 30 dias $) \times 2$ temperaturas) com 5 repetições, cada uma composta por 5 tubérculos de mandioquinhas-salsa.

As avaliações químicas realizadas foram: a) determinação dos teores de sólidos solúveis: em refratômetro digital, segundo Association of Official Analytical Chemistry (1992) e expressos os resultados em ${ }^{\circ}$ Brix; b) açúcares totais: pelo método do Instituto 
Adolfo Lutz (2008) e expressos os resultados em glicídios totais em glicose, por cento $\mathrm{m} / \mathrm{m}$; c) amido: pelo método do Instituto Adolfo Lutz (2008) e expressos os resultados em glicídios não redutores, em amido, por cento $\mathrm{m} / \mathrm{m}$ e d) atividade enzimática da polifenoloxidase, método descrito por Lima, Pastore e Lima (2001), e da peroxidase, seguindo o método descrito por Clemente e Pastore (1998), e expressos os resultados em Absorbância/mL/min.

Para determinar a atividade enzimática da polifenoloxidase (PPO) foi utilizado o método descrito por Lima, Pastore e Lima (2001). Após a mistura de 5.10 $10^{-4} \mathrm{~L}$ do extrato enzimático, com $8 \cdot 10^{-4} \mathrm{~L}$ de solução-tampão fosfato de sódio $\left(1.10^{-4} \mathrm{~mol} \mathrm{~m}^{-3} \mathrm{pH} 6,0\right)$ e $5.10^{-4} \mathrm{~L}$ de solução de catecol $1.10^{-5} \mathrm{~mol} \mathrm{~m}^{-3}$, a solução resultante foi incubada a $30^{\circ} \mathrm{C}$ por $1.800 \mathrm{~s}$. Em seguida, acrescentou-se $8.10^{-4} \mathrm{~L}$ de ácido perclórico $2.10^{-3} \mathrm{~mol} \mathrm{~m}^{-3}$. A leitura foi realizada em espectrofotômetro no comprimento de onda de $395 \mathrm{~nm}$. Uma unidade de atividade de polifenoloxidase foi definida como o aumento de uma unidade de absorbância por minuto $\mathrm{mL}^{-1}$ de amostra.

A atividade enzimática da Peroxidase (POD) foi determinada seguindo o método descrito por Clemente e Pastore (1998). Em $2.10^{-4} \mathrm{~L}$ do extrato enzimático adicionou-se $2,7.10^{-3} \mathrm{~L}$ de peróxido de hidrogênio $0,1 \%$ em solução-tampão fosfato de sódio $\left(1.10^{-4} \mathrm{~mol} \mathrm{~m}^{-3} \mathrm{pH}\right.$ $6,0)$. Em seguida adicionou-se $1 \cdot 10^{-4} \mathrm{~L}$ de solução de odianisidina $1 \%$ em metanol. A leitura foi realizada em espectrofotômetro no comprimento de onda de $460 \mathrm{~nm}$. Uma unidade de atividade de peroxidase foi definida como o aumento de uma unidade de absorbância por minuto $\mathrm{mL}^{-1}$ de amostra.

Os resultados obtidos foram submetidos à análise de variância, quando significativo realizou-se a regressão polinomial a $5 \%$ de probabilidade. As análises estatísticas foram realizadas com o auxílio do programa SISVAR (FERREIRA, 2003).

\section{RESULTADOS E DISCUSSÃO}

O teor de sólidos solúveis das mandioquinhassalsa com e sem revestimento não apresentaram diferenças significativas $(\mathrm{P}>0,05)$; entretanto, no decorrer do tempo, pode-se verificar em todas as amostras e independente da temperatura de conservação, que apresentaram tendência a um pequeno decréscimo linear de aproximadamente $0,3{ }^{\circ}$ Brix no início da conservação e um pequeno aumento no final do período estudado (Figura 1) assim como foi observado por Kumar, Singh e Kumar (2004) e Chapper et al. (2002) em batatas conservadas em baixa temperatura. Essa diminuição no início da conservação pode ser atribuída à proteção da quitosana ao produto, e o posterior aumento dos sólidos solúveis, no meio e no final da conservação, pode ser explicado pela possível degradação do revestimento durante o período avaliado. De acordo com Silva (2003) o metabolismo nas condições de anaerobiose pode diminuir a concentração de reservas energéticas em razão do consumo rápido de substratos respiratórios.

Figura 1 - Teores de Sólidos Solúveis da mandioquinhasalsa sem e com revestimento de quitosana nas temperaturas de $0{ }^{\circ} \mathrm{C}$ e $5{ }^{\circ} \mathrm{C}$ e $95 \%$ UR. (Contents of soluble solids of arracacha roots with and without chitosan at $0{ }^{\circ} \mathrm{C}$ and $5{ }^{\circ} \mathrm{C}$ and 95\% RH). Umuarama, UEM, 2010

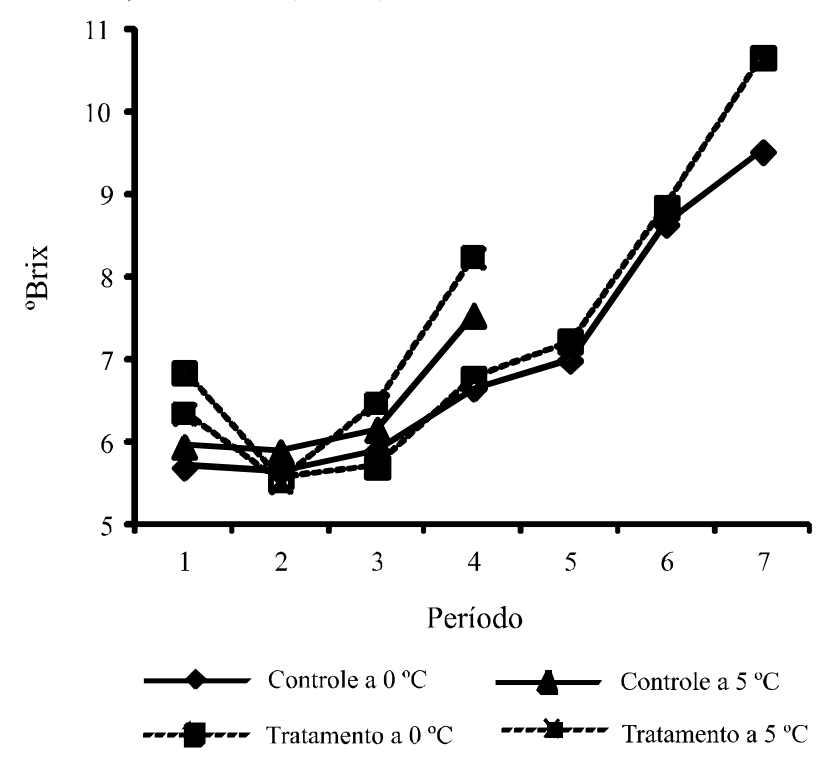

Os teores de açúcares totais na mandioquinhasalsa independente dos tratamentos (com e sem revestimento), nas temperaturas de 0 e $5{ }^{\circ} \mathrm{C}$, não apresentaram diferenças significativas a um $\mathrm{p}<0,05$ (Figura 2), constatando assim que o revestimento com quitosana e o tempo de armazenagem nada influenciou para a redução dos teores de açúcares totais, assim como foi observado por Ribeiro et al. (2007) em mandioquinha-salsa refrigerada e conservada com filme PVC; por Kumar, Singh e Kumar (2004), por Machado, Oliveira e Costa (2011) que trabalharam com pomelos durante 15 dias de armazenamento e Chapper et al. (2002) em batatas conservadas em baixa temperatura, relacionada à atividade das enzimas responsáveis pela degradação do amido e pela redução da atividade respiratória, o que resulta em acúmulo desses carboidratos. 
Figura 2 - Teores de açúcares totais da mandioquinha-salsa sem e com revestimento de quitosana nas temperaturas de $0{ }^{\circ} \mathrm{C}$ e $5{ }^{\circ} \mathrm{C}$ e $95 \%$ UR. (Contents of total sugar and starch of arracacha roots with and without chitosan at $0{ }^{\circ} \mathrm{C}$ and $5{ }^{\circ} \mathrm{C}$ and 95\% RH). Umuarama, UEM, 2010

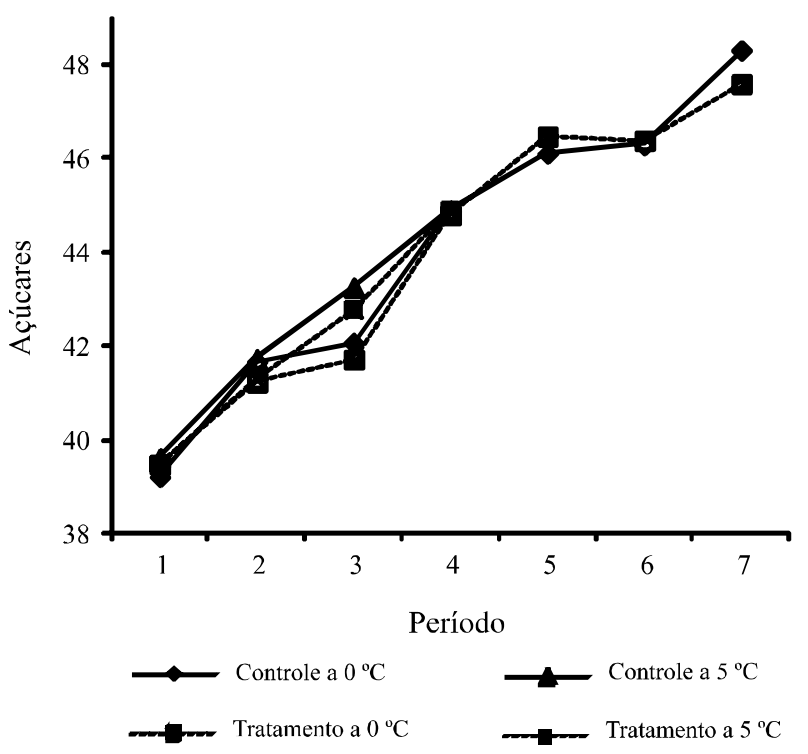

Observando o comportamento do amido na mandioquinha-salsa, constatou-se que os tratamentos com e sem revestimento, nas temperaturas de 0 e $5{ }^{\circ} \mathrm{C}$, não apresentaram diferenças significativas a um $\mathrm{p}<0,05$ (Figura 3). Os teores de amido na mandioquinha-salsa com e sem revestimento, apresentaram um padrão de variação semelhante, sendo o mesmo observado em batata por Chapper et al. (2002) e em mandioquinhasalsa por Ribeiro et al. (2007).

A temperatura, o tempo de conservação e a utilização do revestimento com quitosana afetaram significativamente o aumento da atividade enzimática da polifenoloxidase e da peroxidase $(\mathrm{p}<0,05)$. A atividade enzimática aumentou nas duas temperaturas estudadas, de forma semelhante para PPO e POD. Resultados semelhantes foram encontrados por Menolli et al. (2008) em que a mandioquinha-salsa, armazenada a 5 e $10^{\circ} \mathrm{C}$, apresentou aumento da atividade da polifenoloxidase até o $7^{\circ}$ dia, mantendo-se constante até o $14^{\circ}$ dia e aumentando novamente até o $28^{\circ}$ dia. Para a atividade da peroxidase, houve um aumento até o $7^{\circ}$ dia, tornandose constante até o $21^{\circ}$ e $14^{\circ}$ dia, para as temperaturas de 5 e $10{ }^{\circ} \mathrm{C}$, respectivamente. Para a temperatura de $5{ }^{\circ} \mathrm{C}$ a atividade aumentou até o $28^{\circ}$ dia e, para $10^{\circ} \mathrm{C}$, a atividade foi reduzida.

Segundo Ribeiro et al. (2005), dentre as espécies de vegetais em que ocorrem mudanças físicas dos lipídios saturados das membranas causadas por baixas temperaturas, está a mandioquinha-salsa. As moléculas lipídicas passam do estado gel para o estado gel cristalino, permitindo oxidações enzimáticas, sendo essa mudança lipídica uma resposta primária dos tecidos sensíveis ao frio.

$\mathrm{O}$ aumento, redução e novo aumento da atividade das enzimas PPO e POD (Figuras 4 e 5) podem ser explicados pelas enzimas sequestradoras de radicais

Figura 3 - Teores de amido da mandioquinha-salsa sem e com revestimento de quitosana nas temperaturas de $0{ }^{\circ} \mathrm{C}$ e $5{ }^{\circ} \mathrm{C}$ e 95\% UR. (Contents of starch of arracacha roots with and without chitosan at $0{ }^{\circ} \mathrm{C}$ and $5{ }^{\circ} \mathrm{C}$ and $\left.95 \% \mathrm{RH}\right)$. Umuarama, UEM, 2010

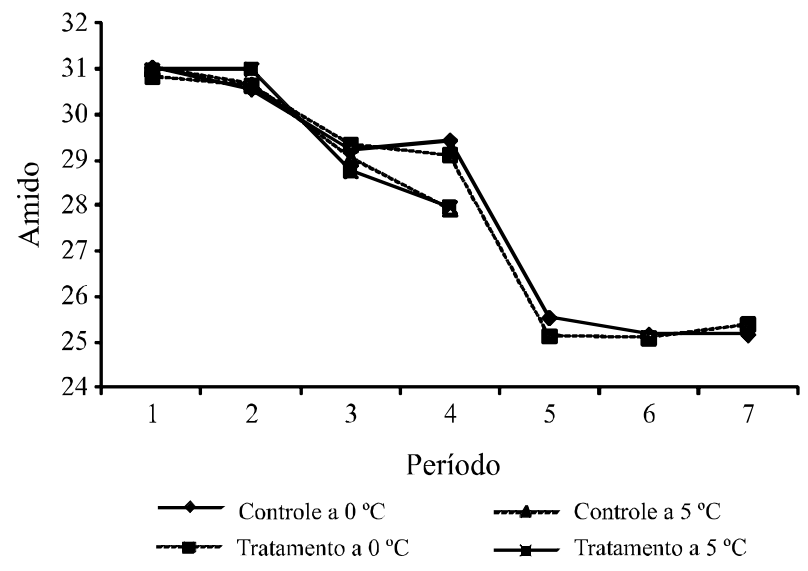

Figura 4 - Atividade da Polifenoloxidase em mandioquinhasalsa, cv. Amarela de Senador Amaral, sem revestimento (controle) e com revestimento (tratamento), durante conservação a $0{ }^{\circ} \mathrm{C}$ e $5{ }^{\circ} \mathrm{C} \pm 0,2{ }^{\circ} \mathrm{C}$ e $95 \%$ UR. (Polifenoloxidase activity in arracacha roots with(cr) and without(sr) chitosan at $0{ }^{\circ} \mathrm{C} \pm 0,2^{\circ} \mathrm{C}$ and $5{ }^{\circ} \mathrm{C} \pm 0,2{ }^{\circ} \mathrm{C}$ and $\left.95 \% \mathrm{RH}\right)$. Umuarama, UEM, 2010

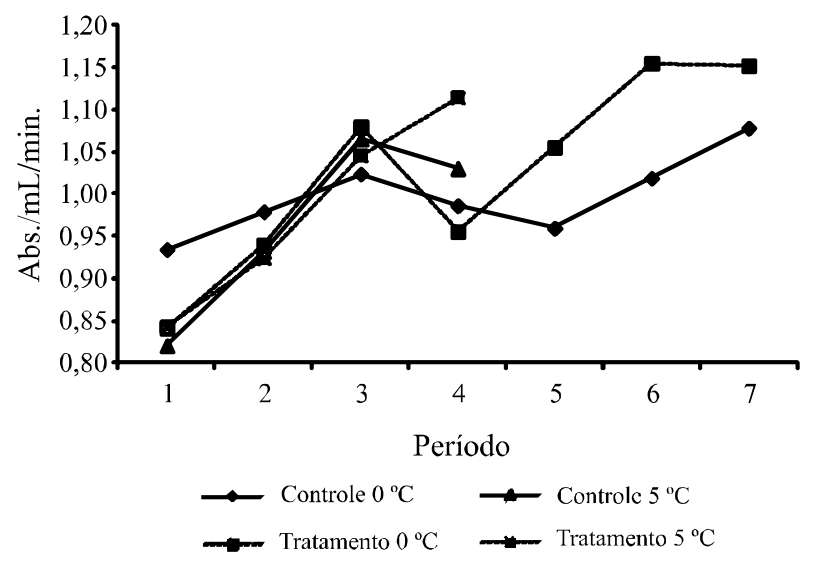


Figura 5 - Atividade da Peroxidase em mandioquinha-salsa, cv. Amarela de Senador Amaral, sem revestimento (controle) e com revestimento (tratamento), durante conservação a $0{ }^{\circ} \mathrm{C}$ e $5{ }^{\circ} \mathrm{C} \pm 0,2{ }^{\circ} \mathrm{C}$ e $95 \%$ UR. (Peroxidase activity in arracacha roots with(cr) and without(sr) chitosan at $0{ }^{\circ} \mathrm{C} \pm 0,2{ }^{\circ} \mathrm{C}$ and $5{ }^{\circ} \mathrm{C}$ $\pm 0,2{ }^{\circ} \mathrm{C}$ and $\left.95 \% \mathrm{RH}\right)$. Umuarama, UEM, 2010

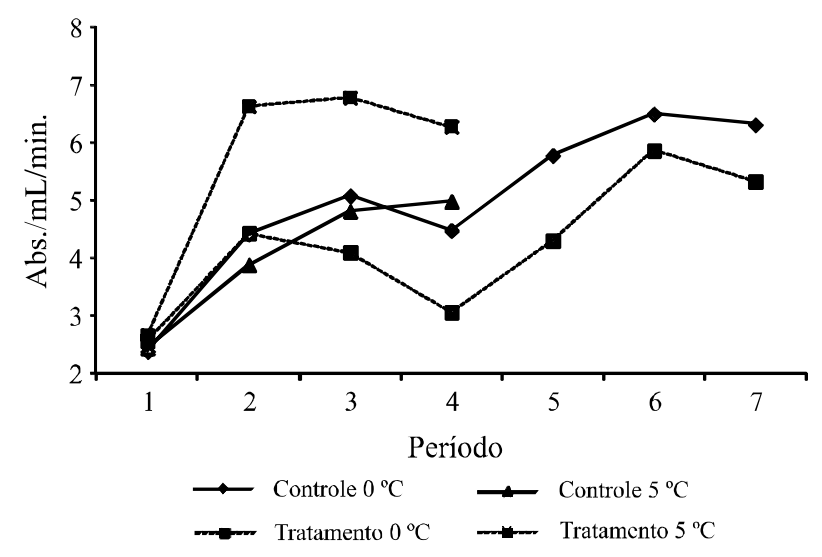

livres. Segundo Chitarra e Chitarra (2005) algumas enzimas especiais, como a superóxido-dismutase; catalase; ascorbato-peroxidase e glutationa-peroxidase são enzimas antioxidantes que atuam nos tecidos vegetais como sequestradoras de radicais livres (oxigênio ativo), os quais são resultantes de estresses oxidativos em muitos sistemas biológicos.

A baixa atividade dessas enzimas pode ser um indicativo do envelhecimento dos tecidos ou de condições especiais de estresse. Por exemplo, pode ser indicativo da sensibilidade de cultivares ao frio. A peroxidase é considerada uma enzima de estresse, estimulada por baixas temperaturas nas espécies que são sensíveis ao frio (KUK et al., 2003).

A quitosana promoveu efeito elicitor de respostas bioquímicas da defesa da mandioquinhasalsa, com aumento significativo nas atividades da polifenoloxidase e da peroxidase, semelhantemente ao encontrado por Liu et al., (2006), quando da utilização de revestimento com quitosana $1 \%$ em tomates.

\section{CONCLUSÃO}

Considerando todos os fatores avaliados, o período de vida útil da mandioquinha-salsa foi de 18 dias a $0{ }^{\circ} \mathrm{C}$, e de 9 dias a $5{ }^{\circ} \mathrm{C}$ superior à vida de prateleira à granel. As mandioquinhas-salsa tratadas com quitosana não apresentaram modificação em suas características físicas e químicas durante o período de armazenamento. Portanto, este polímero, pode ser uma alternativa promissora na pós-colheita de hortaliças.

\section{AGRADECIMENTOS}

Ao CNPQ pela concessão de bolsa de mestrado ao primeiro autor.

\section{REFERÊNCIAS}

ASSOCIATION OF OFFICIAL ANALYTICAL CHEMISTRY. Official methods of analysis of the Association of Official Analytical Chemistry. 12. ed. Washington, 1992. 1015 p.

BAUTISTA-BAÑOS, S. et al. Chitosan as a potencial natural compound to control pre and postharvest diseases of horticultural commodities. Crop Protection, v. 25, n. 2, p. $108-118,2006$

CHAPPER, M. et al. Carboidratos não estruturais em tubérculos de dois genótipos de batata armazenados em duas temperaturas. Horticultura Brasileira, v. 20, n. 4, p. 583$588,2002$.

CHITARRA, M. I. F; CHITARRA, A. B. Pós-colheita de frutas e hortaliças: fisiologia e manuseio. 2. ed. Lavras, MG: UFLA; FAEPE, 2005. $786 \mathrm{p}$.

Clemente, E.; PASTORE, G. M. Peroxidase and polyphenoloxidase, the importance for food technology. Ciência e Tecnologia de Alimentos, v. 32, n. 2, p. 167-171, 1998.

FERREIRA, D. F. Sisvar: versão 4.2. Lavras, MG: UFLA, 2003.

INSTITUTO ADOLFO LUTZ. Normas analíticas, métodos químicos e físicos para análise de alimentos. 5. ed. Brasília, 2008. 919 p.

KUK, Y. I. et al. Antioxidative enzymes offer protection from chilling damage in rice plants. Crop Science, v. 43, n. 6, p. 2109-2117, 2003.

KUMAR, D.; SINGH, B. P.; KUMAR, P. An overview of the factors affecting sugar content of potatoes. Annals of Applied Biology, v. 145, n. 3, p. 247-256, 2004.

LIMA, E. D. P.; PASTORE, G. M.; LIMA, C. A. A. Purificação da enzima polifenoloxidase (PPO) de polpa de pinha (Annona squamosa L.). Ciência e Tecnologia de Alimentos, v. 21, n. 1, p. 98-104, 2001.

LIU, J. et al. Effects of chitosan on control of postharvest diseases and physiological responses of tomato fruit. Postharvest Biology and Technology, v. 44, n. 3, p. 300306, 2006.

MACHADO, F. L. C.; OLIVEIRA, V. S.; COSTA, J. M. C. da. Postharvest quality of grapefruit (Citrus paradisi Macf.) produced from initial plantings in Ceará state, Brazil. Revista Ciencia Agronomica, v. 42, n. 4, p. 965-970, 2011. 
MAYER, A. M.; HAREL, E. Polyphenol oxidases in plants. Phytochemistry, v. 18, n. 2, p. 193-215, 1979.

MELO, B.; SILVA, C. A.; ALVES, P. R. B. Processamento mínimo de hortaliças e frutas. Disponível em: <http://www. fruticultura.iciag,ufu.br/ pminimo.htm>. Acesso em: $15 \mathrm{de}$ ago. 2011.

MENOLLI, L. N. et al. Atuação das enzimas oxidativas no escurecimento causado pela injúria por frio em raízes de batatabaroa. Acta Science Agronomy, v. 30, n. 1, p. 57-63, 2008.

MORETTI, C. L. Manual de processamento mínimo de frutas e hortaliças. Brasília, DF: Embrapa Hortaliças; SEBRAE, 2007. $531 \mathrm{p}$.

OLIVEIRA JUNIOR, E. N. de et al. Alterações pós-colheita da "Fruta-de-Lobo" (Solanum lycocarpum St. Hil.) durante o amadurecimento: análises físico-químicas, químicas e enzimáticas. Revista Brasileira de Fruticultura, v. 26, n. 3, p. 410-413, 2004.
RIBEIRO, R. A. et al. Chilling injury sensitivity in (Arracacia xanthorrhiza) roots. Crop Science, v. 45, n. 2, p. 55-57, 2005.

RIBEIRO, R. A. et al. Vida útil e metabolismo de carboidratos em raízes de mandioquinha-salsa sob refrigeração e filme de PVC. Pesquisa Agropecuária Brasileira, v. 42, n. 4, p. 453458, 2007.

SILVA, V. A. Fisiologia de cenoura minimamente processada. 2003. 78 f. (Dissertação de Mestrado) - Universidade Federal de Viçosa, Viçosa-MG, 2003.

SOUZA, R. M.; HENZ, G. P.; PEIXOTO, J. R. Incidência de injúrias mecânicas em raízes de mandioquinha-salsa na cadeia pós-colheita. Horticultura Brasileira, v. 21, n. 4, p. 712-718, 2003.

WANG, G. Inhibition and inactivation of five species of foodborne pathogens by chitosan. Journal of Food Protection, v. 55, p. 916-919, 1992. 